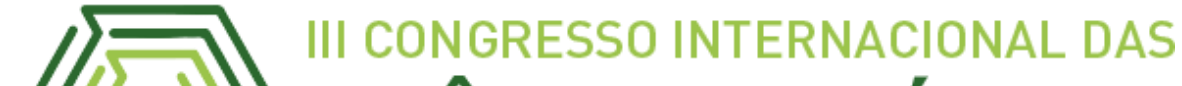 CIÊNCIAS AGRÁRIAS \\ COINTER - PDVAGRO 2018
}

\section{COMPOSIÇÃO TECIDUAL DA PERNA DE OVINOS ALIMENTADOS COM PALMA FORRAGEIRA EM SUBSTITUIÇÃO A CANA DE AÇÚCAR}

\section{LEG TISSUE COMPOSITION OF LAMBS FED SPINELESS CACTUS AS A REPLACEMENT FOR SUGARCANE \\ Apresentação: Pôster}

Dayane Beatriz De Melo Pessoa ${ }^{1}$; Marcelo de Andrade Ferreira $^{2}$; $\underline{\text { Carlos Henrique do }}$ Nascimento $^{3}$; Ana Caroline Cerqueira de Melo ${ }^{4}$; Juliana Paula Felipe de Oliveira- ${ }^{5}$

\section{DOI: https://doi.org/10.31692/2526-7701.IIICOINTERPDVAGRO.2018.00388}

\section{Introdução}

Seja em decorrência de aspectos socioeconômicos, culturais ou, ainda, aspectos ligados à adaptabilidade do pequeno ruminante, é fato que o semiárido nordestino é naturalmente vocacionado para o desenvolvimento da ovinocultura de corte. Mas ainda existem diversos problemas que interferem na eficiência produtiva da região. Embora existam outros pontos a serem trabalhados no estabelecimento da cadeia produtiva, os problemas de ordem nutricional decorrentes da sazonalidade na oferta de volumosos são majoritariamente responsáveis pela insuficiente e irriegular oferta de carne ovina ao mercado (Alves et al., 2014; Silva et al., 2010).

Desta forma, a busca por ingredientes adaptados à região, menos onerosos e de mais fácil acesso é vista como uma estratégia para produzir carcaças com padrão de qualidade diferenciado, para que chegue ao consumidor um produto final com características adequadas e padronizadas. Nesse contexto, a palma forrageira surge como potencial solução por apresentar adaptação às regiões semiáridas, alta produção de matéria seca por unidade de área e principalmente por ser uma forrageira com alto teor de energia. Porém, seu uso pelos ruminantes é limitado pelo baixo teor de fibra em detergente neutro (FDN) em sua

${ }^{1}$ Graduação em Zootecnia, Universidade Federal do Rio Grande do Norte, dayanebeatriz98@hotmail.com

2 Professor Titular, Departamento de Zootecnia, Universidade Federal Rural de Pernambuco, marcelo.aferreira@ufrpe.br

${ }^{3}$ Graduando em Zootecnia, Universidade Federal do Rio Grande do Norte, henrike9@ hotmail.com

${ }^{4}$ Doutoranda em Ciência Animal, Universidade da Flórida, carolcmelo@hotmail.com

5 Professora Substituta, Departamento de Zootecnia, Universidade Federal do Rio Grande do Norte, jupaula.oliv@yahoo.com.br
Formatado: Fonte: Negrito 
composição, havendo necessidade de associá-la a uma fonte de fibra com alta efetividade (Monteiro et al., 2014). Essa fonte poderia ser a cana-de-açúcar, que nos últimos anos, em função da crise da indústria sucroalcooleira, passou a ser utilizada em grande escala pelos pecuaristas na região semiárida do Nordeste brasileiro em virtude da maior disponibilidade e menor custo, quando comparada a outros volumosos.

Com isso, o objetivo do estudo foi avaliar a composição tecidual da perna de ovinos alimentados com palma forrageira (Nopallea cochenillifera Salm Dyck) em substituição a cana de açúcar.

\section{Fundamentação Teórica}

A palma apresenta-se como uma alternativa muito utilizada em regiões semiáridas (Leite et al., 2014). Embora a palma seja uma excelente fonte de energia, rica em carboidratos não fibrosos e nutrientes digestíveis totais, esta não deve ser ofertada como fonte única de volumosos na dieta de ruminantes, tendo em vista os baixos teores de fibra em detergente neutro (FDN) e matéria seca (Ferreira et al., 2007). Com isso a inclusão de fontes de fibra e dm dietas contendo palma como volumoso é imprescindível para maximizar o aproveitamento desta forrageira para o desempenho animal.

De acordo com Macome et al. (2011), o conceito de melhor carcaça está amplamente relacionado com alta proporção de músculos e menor proporção de gordura, levando em consideração as preferências regionais. Fatores como idade sexo-, raça e nutrição influenciam no crescimento e no desenvolvimento dos músculos, na deposição de gordura e, consequentemente, na- qualidade da carne (Casey \& Webb, 2010). Porém, em sistemas de produção, o nível nutricional dos animais é,é sem dúvidas, o fator de maior interferência na qualidade das carcaças comercializadas (Ribeiro et al., 2009).

\section{Metodologia}

O experimento foi conduzido no Departamento de Zootecnia da Universidade Federal Rural de Pernambuco. Foram utilizados 36 animais da raça Santa Inês, machos, não castrados, com peso inicial médio de $22 \pm 2,3 \mathrm{~kg}$ e quatro meses de idade, distribuídos num delineamento de blocos ao acaso com quatro níveis de substituição (0, 33, 66 e 100\% na MS) da cana-de-açúcar pela palma forrageira e oito repetições.

Quatro dietas completas foram formuladas (relação volumoso:-concentrado 
48:52) utilizando-se como alimentos volumosos a cana-de-açúcar e palma miúda. Os ingredientes utilizados nos concentrados foram milho moído, farelo de soja, farelo de trigo, ureia, sal comum e suplemento mineral. As dietas foram formuladas de acordo com as recomendações do NRC (2007) para atender as exigências nutricionais de um ovino com 25 $\mathrm{kg}$ de peso corporal, com ganho de peso de $200 \mathrm{~g} /$ dia sendo todas isoprotéicas.

O ensaio teve duração total de 100 dias, sendo os primeiros 30 dias destinados à adaptação dos animais às instalações e à rotina experimental e os 70 restantes utilizados para coleta de dados e amostras. As dietas foram fornecidas duas vezes ao dia ( $8 \mathrm{~h}$ e $15 \mathrm{~h}$ ). Diariamente, as sobras eram coletadas e pesadas para ajuste da oferta e cálculo do consumo de matéria seca. Após os 70 dias experimentais, os animais foram submetidos a jejum de sólidos e dieta hídrica de 12 horas para, então, serem abatidos.

Para determinação desta composição, foram dissecadas as 36 pernas esquerdas previamente armazenadas, as quais foram descongeladas gradativamente a temperatura de aproximadamente $4^{\circ} \mathrm{C}$ durante 24 horas. Com o auxílio de bisturi, pinça e tesoura foram separados os seguintes grupos tissulares: gordura subcutânea (localizada entre a pele e as massas do tecido muscular), gordura intermuscular (gordura que ocupa os espaços entre os músculos), músculo (peso total dos músculos dissecados após remoção completa de toda gordura aderida), osso (peso de todos os ossos da perna) e outros tecidos (tendões, linfonodos, nervos e vasos sanguíneos).

Após a dissecação da perna foram obtidos os pesos e rendimentos dos tecidos dissecados, sendo que a porcentagem dos componentes teciduais foi calculada em relação ao peso reconstituído da perna após a dissecação. Posteriormente foram calculadas as relações músculo:osso e músculo:gordura conforme Cesar \& Souza (2007).

Durante a dissecação os cinco principais músculos que envolvem o fêmur (Biceps femures, Semimembranosus, Semitendinosus, Quadriceps femoris e Adductor) foram retirados e posteriormente pesados para cálculo do índice de musculosidade da perna de acordo com a seguinte fórmula: $\mathrm{IMP}=\sqrt{ }(\mathrm{P} 5 \mathrm{M} / \mathrm{CF}) / \mathrm{CF}$, onde $\mathrm{P} 5 \mathrm{M}$ representa o peso dos cinco músculos $(\mathrm{g})$ e CF o comprimento do fêmur (cm) (Purchas et al., 1991).

O delineamento experimental foi o de blocos ao acaso, sendo o peso inicial dos animais o critério para formação dos blocos. Foi adotado 0,05 de significância como nível crítico de probabilidade para o erro tipo I. Os dados obtidos foram analisados utilizando-se o procedimento MIXED do SAS 9.4 considerando efeitos aleatórios, as variáveis bloco e 
bloco*tratamento de acordo com o seguinte modelo:

$$
\mathrm{Yijk}=\mu+\tau \mathrm{i}+\beta \mathrm{j}+\tau \beta \mathrm{ij}+\varepsilon \mathrm{ijk} \text {, onde: }
$$

Yijk= valor observado $\mathrm{k}$ na unidade experimental que recebeu o tratamento $\mathrm{i}$, repetição $\mathrm{j} ; \mu=$ média geral comum a todas as observações; $\tau i=$ efeito do tratamento $i ; \beta j=$ efeito do bloco $j$; $\tau \beta \mathrm{ij}=$ efeito de interação tratamento $\mathrm{i}$ e bloco $\mathrm{j}$; cijk $=$ erro aleatório com média 0 e variância $\sigma^{2}$.

\section{Resultados e Discussões}

Dentre os componentes teciduais da perna avaliados (Tabela 1), os músculos foram os que apresentaram o maior peso (1618,80 g), seguido de ossos $(391,09 \mathrm{~g})$ e gordura $(326,09 \mathrm{~g})$. Esses componentes teciduais apresentam ordem de desenvolvimento diferentes onde, segundo Wood et al. (1980), o tecido ósseo apresenta crescimento mais precoce, seguido do muscular e, por último, do tecido adiposo. Analisando esses valores, em especial o peso muscular, podese verificar a aptidão que o ovino Santa Inês possui para produção de carne, sobretudo quando observamos o percentual médio de deposição muscular de 67,82\%.

Para a composição tecidual, foi verificado efeito quadrático para o peso da perna, músculos, gordura subcutânea e gordura total com valores máximos estimados em 2743,79; 1821,9; 163,75 e 266,46 g com 43,29; 44,70; 52,89 e 51,18\% de substituição respectivamente, podendo ser uma provável consequência no efeito quadrático observado para o consumo de nutrientes, em especial de energia.

Tabela 1 - Consumo de nutrientes e composição tecidual da perna de ovinos da raça Santa Inês alimentados com palma forrageira em substituição a cana-de-açúcar. Fonte: Própria

\begin{tabular}{|c|c|c|c|c|c|c|c|}
\hline \multirow[t]{2}{*}{ Componente } & \multicolumn{4}{|c|}{ Níveis de substituição (\%) } & \multirow{2}{*}{ EPM } & \multicolumn{2}{|l|}{ Efeito } \\
\hline & 0 & 33 & 66 & 100 & & $\mathrm{~L}$ & Q \\
\hline \multicolumn{8}{|c|}{ CONSUMO DE NUTRIENTES } \\
\hline CMS (kg) & 1,10 & 1,350 & 1,198 & 0,974 & 0,056 & 0,0098 & $<0,0001$ \\
\hline CMOD (kg) & 0,716 & 0,832 & 0,820 & 0,648 & 0,039 & 0,1662 & 0,0003 \\
\hline \multicolumn{8}{|c|}{ COMPOSIÇÃO TECIDUAL } \\
\hline Perna $(g)$ & 2525,9 & 2772,4 & 2652,4 & 2401,3 & 140,60 & 0,3292 & 0,0343 \\
\hline Músculo total (g) & 1652,7 & 1804,4 & 1788,7 & 1557,7 & 82,59 & 0,3598 & 0,0137 \\
\hline Osso total (g) & 494,1 & 549,3 & 497,5 & 517,2 & 32,87 & 0,9009 & 0,5787 \\
\hline Gord. subcut. (g) & 110,1 & 164,7 & 152,5 & 125,8 & 12,14 & 0,4879 & 0,0013 \\
\hline
\end{tabular}




\begin{tabular}{|c|c|c|c|c|c|c|c|}
\hline Gord. interm. (g) & 89,0 & 108,2 & 93,8 & 88,5 & 9,23 & 0,6413 & 0,1186 \\
\hline Gordura total (g) & 199,7 & 273,4 & 246,8 & 215,01 & 17,65 & 0,7646 & 0,0010 \\
\hline Outros tecidos (g) & 54,1 & 65,93 & 60,81 & 60,81 & 8,50 & 0,7011 & 0,4954 \\
\hline Músculo total (\%) & 69,67 & 66,92 & 68,48 & 66,23 & 0,990 & 0,0606 & 0,8038 \\
\hline Osso total $(\%)$ & 20,03 & 20,56 & 19,53 & 22,17 & 0,876 & 0,1699 & 0,2268 \\
\hline Gordura total (\%) & 8,09 & 10,11 & 9,64 & 8,97 & 0,511 & 0,3379 & 0,0128 \\
\hline Outros tecidos $(\%)$ & 2,21 & 2,41 & 2,36 & 2,58 & 0,271 & 0,3837 & 0,9636 \\
\hline Músculo:osso & 3,49 & 3,26 & 3,81 & 3,01 & 0,319 & 0,5417 & 0,3828 \\
\hline Músculo:gordura & 8,78 & 6,64 & 7,38 & 7,65 & 0,505 & 0,2662 & 0,0288 \\
\hline IMP & 0,36 & 0,38 & 0,39 & 0,37 & 0,008 & 0,4493 & 0,0194 \\
\hline
\end{tabular}

Gord. Subcut. = gordura subcutânea; Gord. Interm. = gordura intermuscular.

O índice de musculosidade da perna, que é um dos principais indicativos da quantidade de músculos nesse corte, apresentou comportamento quadrático, com valor máximo estimado em 0,38 com $56,77 \%$ de substituição, acompanhando o consumo de energia. No presente trabalho, a deposição de tecido adiposo na perna acompanhou o comportamento quadrático do consumo de matéria orgânica digestível.

Os componentes tissulares osso e outros tecidos não foram influenciados pela substituição da cana-de-açúcar por palma forrageira. A proporção músculo:gordura foi influenciada pela substituição, apresentando comportamento quadrático com valor máximo de 6,69 com 61,9\% de substituição. Já a relação músculo:osso não sofreu influência alguma com a substituição provavelmente pelo fato do peso dos ossos não terem alterado.

A relação músculo:osso é uma medida objetiva frequentemente associada à maior deposição de massa muscular (Purchas et al., 1991). Todavia, Monte et al. (2007) afirmaram que, do ponto de vista da qualidade da carne, a relação músculo:gordura pode ser considerada a mais importante, visto que a presença de gordura tem grande importância na aceitação da carne, pois influencia nas características de textura, suculência e sabor.

\section{Conclusões}

Recomenda-se a substituição da cana-de-açúcar pela palma forrageira em $44 \%$ tendo em vista que esse nível melhorou a maioria das características de carcaça e composição tecidual da perna. 


\section{Referências}

ALVES, L.G.C.; OSÓRIO, J.C.S.; FERNANDES, A.R.M. Produção de carne ovina com foco no consumidor. Enciclopédia Biosfera, Centro Científico Conhecer. Goiânia, v. 10 , n. 18, p. 2399-2415, 2014.

CASEY, N. H.; WEBB, E. C. Managing goat production for meat quality. Small Ruminant Resarch, v. 89, n 2-3, p. 218-224, 2010.

CEZAR, M. F., SOUZA, W. H. Carcaças Ovinas e Caprinas: obtenção, avaliação e classificação. Uberaba : Editora Agropecuária Tropical, p. 147, 2007.

FERREIRA, M. A.; SILVA, F. M. DA; BISPO, S. V. Estratégias na suplementação de vacas leiteiras no semi-árido do Brasil. Revista Brasileira de Zootecnia, v. 38, p. 322-329, 2009.

LEITE, M. L. M. V.; SILVA, D. S.; ANDRADE, A. P. Caracterização da produção de palma forrageira no Cariri Paraibano. Revista Caatinga, V. 2, n. 2, p. 192-200, 2014.

MACOME, F.; LOPES, O.; REGINA, B. Productive performance and carcass characteristics of lambs fed diets containing different levels of palm kernel cake. Revista MVZ Córdoba, v. 16, n. 3, p. 2659-2667, 2011.

MONTE, A.L.S.; SELAIVE-VILLARROEL, A. B.; PÉREZ, J. R. O. Rendimento de cortes comerciais e composição tecidual da carcaça de cabritos mestiços. Revista Brasileira de Zootecnia, v. 36, p. 2127-2133, 2007.

MONTEIRO, C. C. F., MELO, A. A. S., CAMPOS, J. M .S. Replacement of wheat bran with spineless cactus (Opuntia ficus indica Mill cv Gigante) and urea in the diets of Holstein x Gyr heifers. Tropical Animal Health and Production, v. 46, p. 1149-1154, 2014.

PURCHAS, R.W.; DAVIES, A. S.; ABDULLAH, A.Y. An objective measure of muscularity: changes with animal growth and differences between genetic lines of Southdown sheep. Meat Science, v. 30, p. 81-94, 1991.

RIBEIRO, T. M. D.; MONTEIRO, A. L. G.; PRADO, O. R. Desempenho e características das carcaças de cordeiros em quatro sistemas de produção. Revista Brasileira de Saúde e Produção Animal, v. 10, n. 2, p. 366-378, 2009.

SILVA, N. V.; COSTA, R. G.; FREITAS, C. R. G.; GALINDO, M. C. T.; SILVA, L. S. Alimentação de ovinos em regiões semiáridas do Brasil, Acta Veterinaria Brasilica, v. 4, n. 4, p.233-241, 2010.

WOOD, J. D.; MCFIE, J. H. D.; POMEROY, R. W.; TWINN, D. I. Carcass composition in four shepp breeds: the importance of type of breed and stage of maturity. Animal Production, v. 30, n. 1, p. $135-252,1980$ 